\title{
Learning the ecological niche
}

\section{Tore Slagsvold $^{1, *}$ and Karen L. Wiebe ${ }^{2}$}

\author{
${ }^{1}$ Department of Biology, University of Oslo, PO Box 1066, Blindern, 0316 Oslo, Norway \\ ${ }^{2}$ Department of Biology, University of Saskatchewan, 112 Science Place, Saskatoon, Saskatchewan S7N 5E2, Canada
}

\begin{abstract}
A cornerstone of ecological theory is the ecological niche. Yet little is known about how individuals come to adopt it: whether it is innate or learned. Here, we report a cross-fostering experiment in the wild where we transferred eggs of blue tits, Cyanistes caeruleus, to nests of great tits, Parus major, and vice versa, to quantify the consequences of being reared in a different social context, but in an environment otherwise natural to the birds. We show that early learning causes a shift in the feeding niche in the direction of the foster species and that this shift lasts for life (foraging conservatism). Both species changed their feeding niches, but the change was greater in the great tit with its less specialized feeding behaviour. The study shows that cultural transmission through early learning is fundamental to the realization of ecological niches, and suggests a mechanism to explain learned habitat preference and sympatric speciation in animals.
\end{abstract}

Keywords: ecological niche; cultural transmission; learning; speciation; foraging conservatism; habitat preferences

\section{INTRODUCTION}

Ecological theory states that each species has a unique niche, which encompasses its habitat and its use of resources in the presence of competition and other biotic interactions (Hutchinson 1959; Krebs 2001; Begon et al. 2005). The theory suggests that niches of closely related species are usually separated, facilitating coexistence by reducing competition if food is limited. Classic textbook examples are habitat use by Galápagos finches (Grant 1986; Grant \& Grant 2003) and the spatial segregation in trees by small passerine bird species foraging in mixed flocks, such as warblers (MacArthur 1958; Price et al. 2000) and titmice (Lack 1971; Alatalo et al. 1987; Suhonen et al. 1994). However, although feeding niches are well documented, little is known about how individuals come to adopt them, whether they are innate and fixed at birth or else learned (Immelmann 1975; Marchetti \& Price 1989; Davis \& Stamps 2004; Tonnis et al. 2005). Here, we report a cross-fostering experiment in the wild where we transferred eggs of blue tits, Cyanistes caeruleus, to nests of great tits, Parus major, and vice versa, to quantify the consequences of being reared in a different social context, but in an environment otherwise natural to the birds (Slagsvold et al. 2002).

In the breeding season, blue tits and great tits feed on an abundance of caterpillars in trees and bushes. In winter, the two species forage together in mixed species flocks with little overlap in feeding niches, the blue tit feeding mainly high in trees on twigs and buds, and the great tit mainly on the ground or on the trunks and thicker branches of trees (Lack 1971; Suhonen et al. 1994). We cross-fostered young birds between the two species in a woodland near Oslo, Norway, and observed their foraging behaviour at two times of the year, in early autumn soon after they became independent, and in early spring before breeding started.

*Author for correspondence (tore.slagsvold@bio.uio.no).

\section{MATERIAL AND METHODS}

Cross-fostering of blue tits and great tits has been carried out since 1997 in an area of $1.6 \mathrm{~km}^{2}$, with about 450 nest boxes in mixed deciduous-coniferous woodland near Oslo $\left(6000^{\circ} \mathrm{N}\right.$, $1038^{\circ}$ E; Slagsvold \& Hansen 2001; Slagsvold et al. 2002). The research has been approved by the appropriate authorities of Norway regulating research with animals. We determined which birds owned the territories and boxes in March and April 2005, and observed foraging in early spring (8-30 April), and also in early autumn (16 August-30 September) in 2005. In spring, we focused on all known cross-fostered birds and observed a similar number of unmanipulated (control) birds inhabiting the nearest territories to the cross-fostered ones. The cross-fostered and control birds reared in our nest boxes could be identified by a unique combination of colour rings. As controls, we also included immigrants that were captured and ringed (usually by mistnetting in autumn) and which were aged by plumage as first year (juvenile) or older birds (adult) assumed to be in their second year of life.

In autumn, the location of adult birds was less predictable than in spring because individuals were less territorial and juveniles foraged in flocks. We therefore attempted to record the foraging behaviour of every bird encountered as we visited all parts of the study area and so sample sizes were more variable between treatment groups in autumn than in spring. Over the years, there were too many nestlings to assign a unique combination of colour leg rings to each. Hence, in 2005, we assigned each of the four treatment groups a unique subset of colours and made use of 12 different combinations in each group. Unringed juveniles were included as controls, and we assumed that juveniles with the same ring combination (or those unringed) were different individuals if seen in different flocks. Yearlings and adults were sexed from their breeding behaviour in March-June (e.g. only females build nests and incubate). Juveniles observed in the autumn were not sexed.

The sex ratio and age in years ( $\log x+1$ transformed) of focal birds did not differ among treatment groups in either the spring sample $\left(n=101,56 \%\right.$ males; $\chi^{2}$-test, $p=0.52$; range 

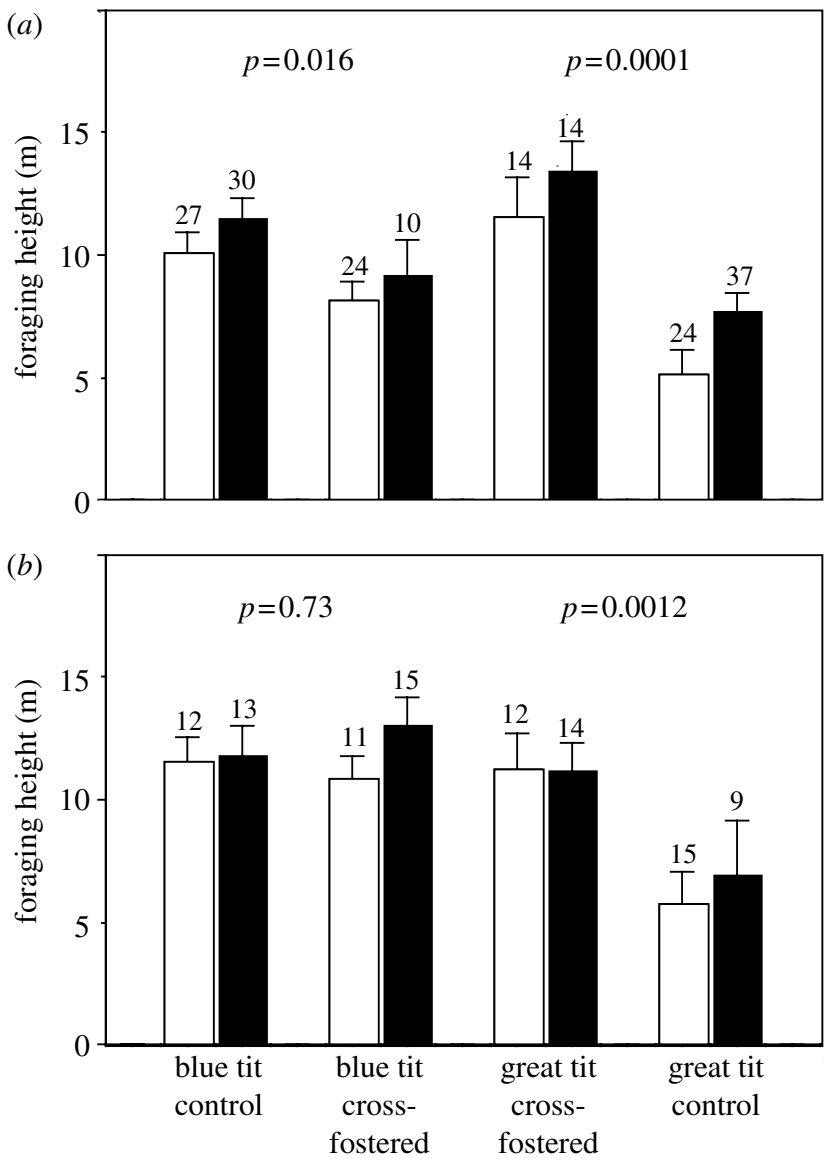

Figure 1. Foraging height (mean+s.e.m.) for blue tits and great tits: $(a)$ in August-September, and $(b)$ in April. Open bars, juveniles; filled bars, older birds. Cross-fostered birds were reared by the other species. Sample sizes are shown above bars. The $p$-values refer to $t$-tests between crossfostered birds and controls. Age of focal bird had no significant effect in these comparisons.

1-7 years old; ANOVA, $p=0.26)$ or the autumn sample (68\% males, $n=92$, only possible to sex adults; $\chi^{2}$-test, $p=0.93$; range $0-4$ years old, $n=180$; ANOVA, $p=0.33$ ). Similarly, the date of observation did not differ among the treatment groups in either spring (ANOVA, $p=0.46$ ) or autumn $(p=0.27)$.

The observation period began after we identified the focal bird from its leg rings. We collected a total of $120 \mathrm{~s}$ of foraging observations (usually a consecutive period), only once per bird per season. If the focal bird moved out of sight or engaged in activities other than foraging before the $120 \mathrm{~s}$ elapsed, we spent a further $10 \mathrm{~min}$ in the area in an effort to resight it, accepting foraging observations that lasted at least $5 \mathrm{~s}$. Observation bouts were longer for blue tits than for great tits in spring (ANOVA, $n=101, p=0.0041$ ), but not in autumn (same test, $n=180, p>0.05$ ). However, there was no significant difference in observation time between crossfostered birds and controls for either the spring or the autumn data (ANOVA, same samples, $p>0.05$ ).

Foraging height, measured with a Suunto height recorder, was calculated as the mean of the heights at the start and end of the observation period. Most control blue tits fed from buds and leaves, or twigs with a diameter less than $2 \mathrm{~cm}$ (usually much thinner), whereas most control great tits fed from the trunk and branches thicker than $2 \mathrm{~cm}$ or on the ground. We graphed the mean percentage of time spent foraging in twigs to illustrate the results, but used a logistic
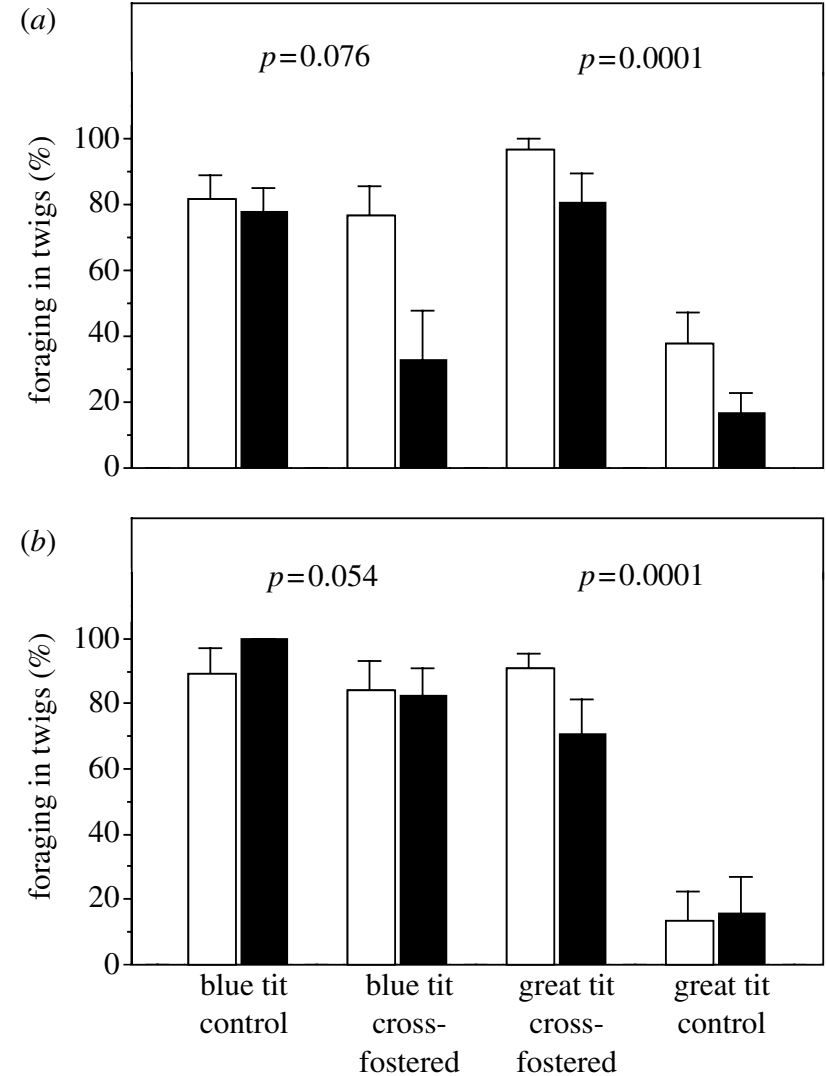

Figure 2. Percentage of time foraging in twigs (mean + s.e.m.) for blue tits and great tits: $(a)$ in August-September and $(b)$ in April. Sample sizes and symbols as in figure 1, except that $p$-values refer to logistic regression for great tits where age of focal bird had a significant effect ( $p$-value refers to the model with both treatment and age included), and to $U$-tests in the other comparisons where age did not have any significant effect.

regression on whether or not the bird spent any time in twigs because most birds either were in twigs all the time, or not at all. The statistical tests are two-tailed.

\section{RESULTS}

As a first step, we confirmed the prerequisite that there was a marked difference in foraging ecology between blue tits and great tits in our populations of unmanipulated (control) birds. Control blue tits foraged higher above the ground than control great tits both in autumn ( $t$-test, $t_{176}=4.58, p=0.0001$; figure $\left.1 a\right)$ and in spring $\left(t_{47}=4.00\right.$, $p=0.0002$; figure $1 b$ ), and they also spent more time foraging in twigs in autumn ( $U$-test, $z=-6.04, n_{1}=57$, $n_{2}=61, p=0.0001$; figure $\left.2 a\right)$ and in spring $(z=-5.75$, $n_{1}=25, n_{2}=24, p=0.0001$; figure $2 b$ ).

If foraging behaviour is influenced by early learning, the behaviour of cross-fostered birds should differ from controls of the same species and be more similar to their foster species. This was confirmed in foraging heights, although the effect was stronger in great tits than in blue tits (figure 1). Factorial ANOVA of foraging height showed a significant effect of treatment (cross-fostered versus control) both for the autumn $(p=0.030)$ and the spring $(p=0.004)$ data, and the interaction term between species and treatment was also significant for both periods (autumn, $p=0.0001$; spring, $p=0.014$; table 1 ). In autumn, juveniles foraged at lower heights than adults 
Table 1. Differences in foraging behaviour between blue tits and great tits, and between two treatments (cross-fostered and control). (Interaction term is included only when significant. Statistics are given as $F$-values for foraging height (factorial ANOVA), and $\chi^{2}$-values for foraging in twigs (logistic regression). ${ }^{*} p<0.05,{ }^{* *} p<0.01,{ }^{* * *} p<0.001$.)

\begin{tabular}{llllll}
\hline & & & & & \\
\cline { 4 - 5 } dependent variable & season & $n$ & species & treatment & interaction \\
\hline foraging height & autumn & 180 & 0.02 & $4.81^{*}$ & $28.61^{* * *}$ \\
foraging in twigs & spring & 101 & $12.07^{* * *}$ & $8.58^{* *}$ & $6.29^{*}$ \\
& autumn & 180 & 0.00 & $8.48^{* *}$ & $16.47^{* *}$ \\
\hline
\end{tabular}

$\left(F_{1,172}=4.64, p=0.033\right)$, but there was no interaction effect of age with species or treatment $(p>0.05)$. In spring, there was no effect of age, and the sex of the focal bird did not add significantly to the model in any period $(p>0.05)$.

The cross-fostered birds also changed the amount they foraged in twigs in the direction of the foster species; more so for the great tit than for the blue tit (figure 2). Logistic regression of whether or not a bird foraged in twigs showed a significant effect of treatment in both periods (autumn, $p=0.004$; spring, $p<0.0001$ ), and a significant interaction between species and treatment for autumn $(p<0.0001$; table 1), but not for spring $(p>0.05)$. In autumn, juveniles tended to forage more often in twigs than adults $\left(\chi_{1}^{2}=6.52, p=0.011\right)$, but there was no interaction effect of age with species or treatment $(p>0.05)$. As with foraging height, there was no effect of age in spring or sex of the focal bird in any period $(p>0.05)$.

The above global analyses showed that juveniles were no more affected by cross-fostering when compared with adults because neither any interaction term between age and treatment nor any interaction between species, treatment and age was significant. In a more detailed test, we compared the foraging height and the proportion of time spent foraging in twigs, of a cross-fostered bird with its actual age in years (age $\log x+1$ transformed; range: in blue tits, $0-4$ years in autumn and $1-4$ years in spring; in great tits, $0-4$ years in autumn and 1-7 years in spring). If cross-fostered blue tits adjusted their foraging behaviour in the direction of conspecific controls over their lifespan, the correlations should have been positive. This was not the case as correlations were non-significant or negative (height in autumn, Pearson's $r=0.14, n=34$, $p=0.44$; spring, $r=0.20, n=26, p=0.32$; twigs in autumn, Spearman's $r_{\mathrm{s}}=-0.45, n=34, p=0.010$; spring, $\left.r_{\mathrm{s}}=-0.07, n=26, p=0.74\right)$. Likewise, we would expect significant, negative correlations in the case of crossfostered great tits, but this was not found (height in autumn, $r=0.28, n=28, p=0.15$; spring, $r=0.02, n=26$, $p=0.94$; twigs in autumn, $r_{\mathrm{s}}=-0.18, n=28, p=0.36$; spring, $\left.r_{\mathrm{s}}=-0.20, n=26, p=0.31\right)$. We conclude that early learning from a different species caused a shift in the normal feeding niche that lasted for life.

\section{DISCUSSION}

Feeding niches may result from both morphological and behavioural differences among species. Blue tits are better adapted anatomically than great tits to forage from buds and leaves of tiny twigs because they have longer and stronger feet which allow them to hang upside down more easily while foraging than great tits (Moreno \& Carrascal
1993; Rytkönen \& Krams 2003). A genetically fixed and specialized morphology may explain why blue tits were less affected by cross-fostering than great tits. Blue tits are socially subordinate to great tits, but the shifts of feeding niches in our study cannot be explained by social dominance rank. Although cross-fostered birds tended to lose fights over food at common feeding sites in winter with control birds of the same species and sex (Hansen $\&$ Slagsvold 2004), they were free to choose feeding locations in their respective breeding territories in spring where they were socially dominant (Hansen \& Slagsvold 2003). Moreover, in both tit species, males are socially dominant to females and this was also true for crossfostered males versus control females in winter (Hansen \& Slagsvold 2004). Yet, our statistical analysis indicated neither any influence of sex on foraging behaviour in autumn or spring nor any significant interaction between sex and treatment.

Studies of tits in captivity show not only that feeding skill and choice of foraging site have strong innate biases (Partridge 1974, 1979), but also that the birds may learn new feeding techniques and food items after they become independent (Fisher \& Hinde 1949; Rowe et al. 2004). Therefore, it was remarkable in our study that early learning had such a strong and lasting effect on the foraging behaviour of birds in the wild. We expected that cross-fostered birds would shift their foraging niche by trial-and-error, back to the normal niche for the species, assuming that control birds had the optimal foraging patterns in the local environment. In contrast, the foraging behaviour of the parents, and possibly other individuals perceived as conspecifics, seemed to be imprinted on the young ones, probably because juveniles avoid costly trialand-error learning by copying behaviour that has proven to be successful for their parents (Galef \& Laland 2005). Our study is therefore consistent with recent findings that animals may be reluctant to include new prey items in their diets (Marples et al. 1998; Marples \& Kelly 1999; Thomas et al. 2004), which may be explained by the advantages of search images, the experience with prey handling and the informational costs of a generalist foraging strategy (Dall \& Cuthill 1997; Marples et al. 2005). The present study shows that such dietary conservatism may also be found in a food generalist (the great tit) and include not only prey types but also feeding sites (learned foraging habitat preference). Strong foraging conservatism means that, in order to benefit from early experience, a bird should prefer to settle in a habitat that is similar to its natal rearing site, and also to be philopatric to its breeding area once settled (Stephens 1991; Beltman \& Metz 2005). If foraging efficiency 
increases with social learning of prey types and the location of those prey, our results provide an ultimate explanation for why birds are imprinted on their natal habitat (Davis \& Stamps 2004).

Recent theory and models suggest that learned habitat preference is even more potent a force in sympatric speciation than genetic-based habitat preference (Beltman \& Metz 2005). Once populations become behaviourally imprinted on certain habitats, reproductive isolation may occur and subsequently facilitate genetic divergence among groups (Beltman et al. 2004; Tonnis et al. 2005). The idea that learning promotes speciation (Immelmann 1975; Beltman et al. 2004; Beltman \& Metz 2005) is supported by our findings because cross-fostering had a greater influence on foraging in great tits than in blue tits and speciation has been much greater in the great tit group than in the blue tit group, although blue tits branched off earlier than did the great tit group (Gill et al. 2005). The theory (Beltman \& Metz 2005) also predicts two endpoints to evolution: specialists with genetic and fixed habitat preferences or generalists with flexible (learned) preferences. Great tits use a much broader range of habitats for breeding than blue tits (Lack 1971) and show a greater reliance on early learning, consistent with the prediction.

In sum, our study provides the first experimental evidence from the wild that the behavioural components serving to separate niches of closely related species are not fixed at birth, but that cultural transmission through early learning is fundamental to the realization of ecological niches, and its influence lasts for life. We also discovered that two closely related species differed in their sensitivity to such early learning. The results provide new insights into how animals come to exploit their environment, suggesting a mechanism to explain learned habitat preference and sympatric speciation.

We thank B. T. Hansen, L. E. Johannessen, L. Kristiansen, M. Landys, P. K. Slagsvold and G. L. Slagsvold for their field assistance.

\section{REFERENCES}

Alatalo, R. V., Eriksson, D., Gustafsson, L. \& Larsson, K. 1987 Exploitation competition influences the use of foraging sites by tits: experimental evidence. Ecology 68, 284-290. (doi:10.2307/1939259)

Begon, M., Townsend, C. R. \& Harper, J. L. 2005 Ecology: from individual to ecosystem. Oxford, UK: Blackwell Publishing.

Beltman, J. B. \& Metz, J. A. J. 2005 Speciation: more likely through a genetic or through a learned habitat preference? Proc. R. Soc. B 272, 1455-1463. (doi:10.1098/rspb.2005. 3104)

Beltman, J. B., Haccou, P. \& ten Cate, C. 2004 Learning and colonization of new niches: a first step toward speciation. Evolution 58, 35-46. (doi:10.1554/03-339)

Dall, S. R. X. \& Cuthill, I. C. 1997 The information costs of generalism. Oikos 80, 197-202.

Davis, J. M. \& Stamps, J. A. 2004 The effect of natal experience on habitat preferences. Trends Ecol. Evol. 19, 411-416. (doi:10.1016/j.tree.2004.04.006)

Fisher, J. \& Hinde, R. A. 1949 The opening of milk bottles by birds. Br. Birds 42, 347-357.

Galef, B. G. J. \& Laland, K. N. 2005 Social learning in animals: empirical studies and theoretical models. BioScience 55, 489-499. (doi:10.1641/0006-3568(2005) 055[0489:SLIAES]2.0.CO;2)
Gill, F. B., Slikas, B. \& Sheldon, F. H. 2005 Phylogeny of titmice (Paridae): II. Species relationships based on sequences of the mitochondrial cytochrome- $B$ gene. $A u k$ 122, 121-143. (doi:10.1642/0004-8038(2005)122[0121: POTPIS]2.0.CO;2)

Grant, P. R. 1986 Ecology and evolution of Darwin's finches. Princeton, NJ: Princeton University Press.

Grant, B. R. \& Grant, P. R. 2003 What Darwin's finches can teach us about the evolutionary origin and regulation of biodiversity. BioScience 53, 965-975. (doi:10.1641/00063568(2003)053 [0965:WDFCTU]2.0.CO;2)

Hansen, L. T. \& Slagsvold, T. 2003 Rival imprinting; interspecifically cross-fostered tits defend their territories against heterospecific intruders. Anim. Behav. 65, 1117-1123. (doi:10.1006/anbe.2003.2146)

Hansen, B. L. T. \& Slagsvold, T. 2004 Early learning affects social dominance: interspecifically cross-fostered tits become subdominant. Behav. Ecol. 15, 262-268. (doi:10.1093/beheco/arh010)

Hutchinson, G. E. 1959 Homage to Santa Rosalia, or why are there so many kinds of animals? Am. Nat. 93, 145-159. (doi:10.1086/282070)

Immelmann, K. 1975 Ecological significance of imprinting and early learning. Annu. Rev. Ecol. Syst. 6, 15-37. (doi:10.1146/annurev.es.06.110175.000311)

Krebs, C. J. 2001 Ecology. San Fransisco, CA: Benjamin Cummings.

Lack, D. 1971 Ecological isolation in birds. London, UK: Blackwell Scientific Publications.

MacArthur, R. H. 1958 Population ecology of some warblers of northeastern coniferous forests. Ecology 39, 599-619. (doi:10.2307/1931600)

Marchetti, K. \& Price, T. 1989 Differences in the foraging of juvenile and adult birds: the importance of developmental constraints. Biol. Rev. 64, 51-70. (doi:10.1086/416130)

Marples, N. M. \& Kelly, D. J. 1999 Neophobia and dietary conservatism: two distinct processes? Evol. Ecol. 13, 641-653. (doi:10.1023/A:1011077731153)

Marples, N. M., Roper, T. J. \& Harper, D. G. C. 1998 Responses of wild birds to novel prey: evidence of dietary conservatism. Oikos 83, 161-165.

Marples, N. M., Kelly, D. J. \& Thomas, R. J. 2005 The evolution of warning coloration is not paradoxical. Evolution 59, 933-940. (doi:10.1554/04-448)

Moreno, E. \& Carrascal, L. M. 1993 Leg morphology and feeding posture in four Parus species: an experimental ecomorphological approach. Ecology 74, 2037-2044. (doi:10.2307/1940849)

Partridge, L. 1974 Habitat selection in titmice. Nature 247, 573-574. (doi:10.1038/247573a0)

Partridge, L. 1979 Differences in behaviour between blue and coal tits reared under identical conditions. Anim. Behav. 27, 120-125. (doi:10.1016/0003-3472(79)90132-5)

Price, T., Lovette, I. J., Bermingham, E., Gibbs, H. L. \& Richman, A. D. 2000 The imprint of history on communities of North American and Asian warblers. Am. Nat. 156, 354-367. (doi:10.1086/303397)

Rowe, C., Linström, L. \& Lyytinen, A. 2004 The importance of pattern similarity between Müllerian mimics in predator avoidance learning. Proc. R. Soc. B 271, 407-413. (doi:10. 1098/rspb.2003.2615)

Rytkönen, S. \& Krams, I. 2003 Does foraging behaviour explain the poor breeding success of great tits Parus major in northern Europe? F. Avian Biol. 34, 288-297. (doi:10. 1034/j.1600-048X.2003.03041.x)

Slagsvold, T. \& Hansen, B. T. 2001 Sexual imprinting and the origin of obligate brood parasitism in birds. Am. Nat. 158, 354-367. (doi:10.1086/321994) 
Slagsvold, T., Hansen, B. T., Johannessen, L. E. \& Lifjeld, L. T. 2002 Mate choice and imprinting in birds studied by cross-fostering in the wild. Proc. $R$. Soc. B 269, 1449-1455. (doi:10.1098/rspb.2002.2045)

Stephens, D. W. 1991 Change, regularity, and value in the evolution of animal learning. Behav. Ecol. 2, 77-89.

Suhonen, J., Alatalo, R. V. \& Gustafsson, L. 1994 Evolution of foraging ecology in Fennoscandian tits (Parus spp.). Proc. R. Soc. B 258, 127-131.
Thomas, R. J., Bartlett, L. A., Marples, N. M., Kelly, D. J. \& Cuthill, I. C. 2004 Prey selection by wild birds can allow novel prey and conspicuous colour morphs to spread in prey populations. Oikos 106, 285-294. (doi:10.1111/ j.0030-1299.2004.13089.x)

Tonnis, B., Grant, P. R., Grant, B. R. \& Petren, K. 2005 Habitat selection and ecological speciation in Galápagos warbler finches (Certhidea olivacea and Certhidea fusca). Proc. R. Soc. B 272, 819-826. (doi:10.1098/rspb.2004.3030) 